\title{
Physician accountability in iatrogenic cerebrospinal fluid leak litigation
}

\author{
Olga Kovalerchik, BA ${ }^{1}$, Leila J. Mady, PhD¹, Peter F. Svider, BA ${ }^{1}$, Andrew C. Mauro, BA², Soly Baredes, MD, \\ FACS ${ }^{1,3}$, James K. Liu, MD ${ }^{1,3,4}$ and Jean Anderson Eloy, MD, FACS ${ }^{1,3,4}$
}

Background: The potentially severe complications resulting from cerebrospinal fluid (CSF) leak makes iatrogenic injury a medicolegal area of concern for otolaryngologists and neurosurgeons. The objectives of this analysis were to study legal outcomes as well as medical and nonmedical elements affecting malpractice litigation.

Methods: Public court records available in the Westlaw legal database (Thomson Reuters, New York, NY) were searched for medical malpractice litigation related to iatrogenic CSF leak. Of the 18 jury verdicts and settlements included, outcomes and awards, patient demographic data, and other factors instrumental in determining legal responsibility were recorded for comparison.

Results: Ten (55.6\%) cases were resolved in the defendant's favor, 2 (11.1\%) resulted in damages awarded by a jury, and $6(33.3 \%)$ were settled out of court before resolution of trial. Mean damages awarded were \$1.1 million, while out of court settlements averaged $\$ 966,887$. Malpractice stemming from patients who underwent endoscopic sinus surgery comprised $77.8 \%$ of cases analyzed. The most frequent alleged factors cited for litigation included having to undergo additional surgery (88.9\%), developing meningitis $(50.0 \%)$, and failing to recognize complications in a timely manner (44.4\%). Perceived deficits in informed consent were alleged in one-third of cases.

Conclusion: Although a slight majority of cases were resolved in the defendant's favor, payments made were considerable, averaging approximately $\$ 1$ million. Strategies to decrease liability and allow patients to make more informed decisions should include clear communication with patients that explicitly states potential risks, such as meningitis, and possible need to undergo additional reparative surgery. (C) 2013 ARS-AAOA, LLC.

Key Words:

liability; malpractice; iatrogenic cerebrospinal fluid leak; negligence; malpractice trial; rhinologic procedures

How to Cite this Article:

Kovalerchik O, Mady LJ, Svider PF, et al. Physician accountability in iatrogenic cerebrospinal fluid leak litigation. Int Forum Allergy Rhinol. 2013;3:722-725.
A dvances in endoscopic endonasal surgery have increased opportunities to treat a wide variety of complex sinonasal conditions in a minimally invasive manner. This expansion in therapeutic repertoire, however, has introduced new challenges and increased incidence of cere-

\footnotetext{
${ }^{1}$ Department of Otolaryngology-Head and Neck Surgery, University of Medicine and Dentistry of New Jersey, New Jersey Medical School, Newark, NJ; ${ }^{2}$, The University of Michigan Law School, Ann Arbor, MI; ${ }^{3}$ Center for Skull Base and Pituitary Surgery, University of Medicine and Dentistry of New Jersey, New Jersey Medical School, Newark, NJ; ${ }^{4}$ Department of Neurological Surgery, University of Medicine and Dentistry of New Jersey, New Jersey Medical School, Newark, NJ

Correspondence to: Jean Anderson Eloy, MD, FACS, Department of

Otolaryngology-Head and Neck Surgery, UMDNJ-New Jersey Medical

School, 90 Bergen St., Suite 8100, Newark, NJ 07103; e-mail:

jean.anderson.eloy@gmail.com

Potential conflict of interest: None provided.

Received: 20 December 2012; Revised: 31 January 2013; Accepted:

19 February 2013

DOI: 10.1002/alr.21169

View this article online at wileyonlinelibrary.com.
}

brospinal fluid (CSF) leaks. While numerous strategies for repair have been developed with varying success, ${ }^{1-12}$ possible complications from an uncontrolled leak may be profound. These may include meningitis, ${ }^{13}$ severe headache, intracranial hypotension, ${ }^{14,15}$ neurologic deficits, and an increased risk of brain herniation. ${ }^{16}$

The serious sequelae associated with CSF leak may lead to malpractice litigation. Legal proceedings related to malpractice have increased dramatically over the past 3 decades and contribute toward rising healthcare costs nationally, with some sources indicating increased expenditures ranging from $\$ 6.5$ to $\$ 10$ billion as a result. ${ }^{17-20}$ Other indirect costs passed down to healthcare consumers include those associated with the practice of defensive medicine, rising malpractice insurance premiums, and decreased access to patients. ${ }^{20-24}$ The nonmonetary price paid by defendant physicians in the medicolegal system can also carry permanent consequences. In particular, perception of physicians by both peers and patients is of particular concern to defendants following litigation. ${ }^{25}$ 
The objectives of this analysis were to characterize elements involved in malpractice stemming from iatrogenic CSF leaks, including case outcome, patient demographic factors, medical complications facilitating litigation, and other factors such as deficits in informed consent. Our hope is that considering strategies to minimize liability may facilitate clearer communication between surgeons and their patients, allowing for a more informed decision.

\section{Materials and methods}

The Westlaw legal database (Thomson Reuters, New York, NY) was searched by 3 authors (O.K., L.M., P.F.S.) for jury verdict and settlement reports relevant to medical malpractice and CSF leaks. This database is a widely used source by legal professionals and nonlegal laypersons that accumulates cases from all publically available state and federal court records. Westlaw obtains records from numerous vendors, which vary by jurisdiction. The source contains no protected patient information and thus does not require institutional review board (IRB) review. (http://static.legalsolutions.thomsonreuters.com/product_ files/westlaw/wlawdoc/wlres/prgde06.pdf). As a results, this database has been used for multiple analyses.

Specific search-terms included "medical malpractice," "CSF," "cerebrospinal fluid," and "cerebral spinal fluid." Out of the 102 initial results, 84 cases were excluded: duplicate cases (2), nonrhinologic intracranial leaks (2), CSF leak incidental and not the reason for the particular case (69), otologic source of CSF leak (2), and leak involving the spine (9). The remaining 18 rhinologic cases were included for analysis.

We contacted Westlaw research support to determine whether these records include all cases. Support staff indicated that the inclusiveness of information varies by vendor. While some jury verdict and settlement reports may be reported voluntarily by attorneys, with the specific objective of publicizing outcome information for future use by others, ${ }^{26,27}$ most jurisdictions may include court records not voluntarily submitted by attorneys involved. Some jurisdictions noted such cases by labeling the legal parties with terms such as "anonymous" and/or "confidential," to avoid revealing identifying information. While numerous out of court settlements may not have progressed to the point of trial and subsequent inclusion into publically available court records, this database has comprehensive information and case details, making it a valuable resource for study of specific topics. Westlaw has been validated through its use in analyses examining litigation related to corticosteroid use, facial paralysis, sinonasal disease, hearing loss, tracheal and laryngeal stenosis, orbital injury, and cranial nerve injury. ${ }^{20,26-32}$

Jury verdict and settlement reports included were examined for legal and medical outcome, damages awarded, patient demographics, procedure performed, medical factors, and complications involved in litigation, as well as the presence of nonmedical factors cited in litigation, such as issues with informed consent, allegedly unnecessary procedure, failure to recognize complications in a timely manner, having to undergo additional surgery as a result of a complication, and whether plaintiff employment was affected. All data was collected in October 2012.

\section{Statistical analysis}

Nonparametric statistical analysis using the Mann-Whitney $\mathrm{U}$ test was used for comparison of continuous variables (MedCalc; MedCalc Software, Mariakerke, Belgium). Statistical significance was set at $p<0.05$.

\section{Results}

Eighteen cases ranging from 1990 to 2010 (median, 2002) were examined after exclusion of nonrelevant court records. There were 7 female $(38.9 \%)$ and 11 male $(61.1 \%)$ plaintiffs. Median patient age was 45 years (range, 1667). Ten $(55.6 \%)$ cases were resolved in the defendant's favor, $2(11.1 \%)$ involved damages awarded by a jury, and $6(33.3 \%)$ were settled out of court before resolution of the trial. The mean of the damages awarded $(\$ 1,104,000$; range, $\$ 300,000-\$ 1,908,000)$ was not statistically different from that of out-of-court settlements $(\$ 966,887$; range, $\$ 575,000-\$ 1.8$ million) (Mann-Whitney U test, $p>0.05$ ).

Fourteen $(77.8 \%)$ cases of litigation stemmed from patients undergoing endoscopic sinus surgery (ESS). There were 2 cases each of non-ESS rhinologic procedures (nasal polyp removal, septoplasty) and complications of CSF leaks from alleged radiologic misdiagnoses also included in the analysis. Otolaryngologists were defendants in 16 cases. Radiologists were named as a defendant in 1 case. One case involved both otolaryngologists and radiologists. Outcome profiles are illustrated in Figure 1.

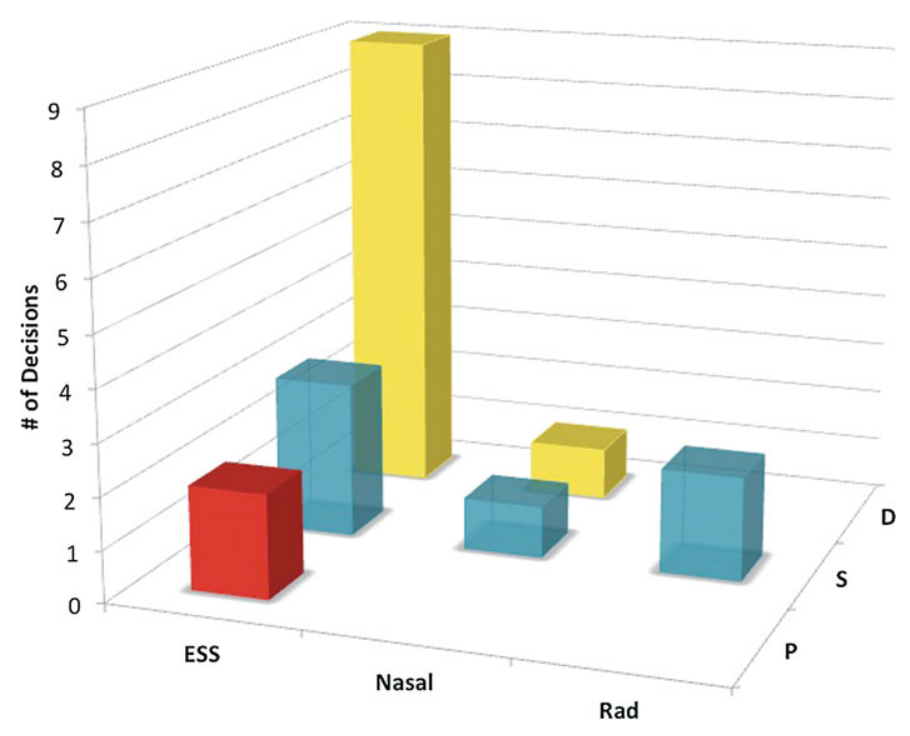

FIGURE 1. Outcome profile of litigation involving CSF leaks. ESS = endoscopic sinus surgery; Nasal = non-ESS rhinologic procedures; $\mathrm{Rad}=$ radiologic misdiagnosis; $D=$ defendant verdict (yellow bar); $S=$ settlement (blue bar), $\mathrm{P}=$ plaintiff verdict (red bar). 


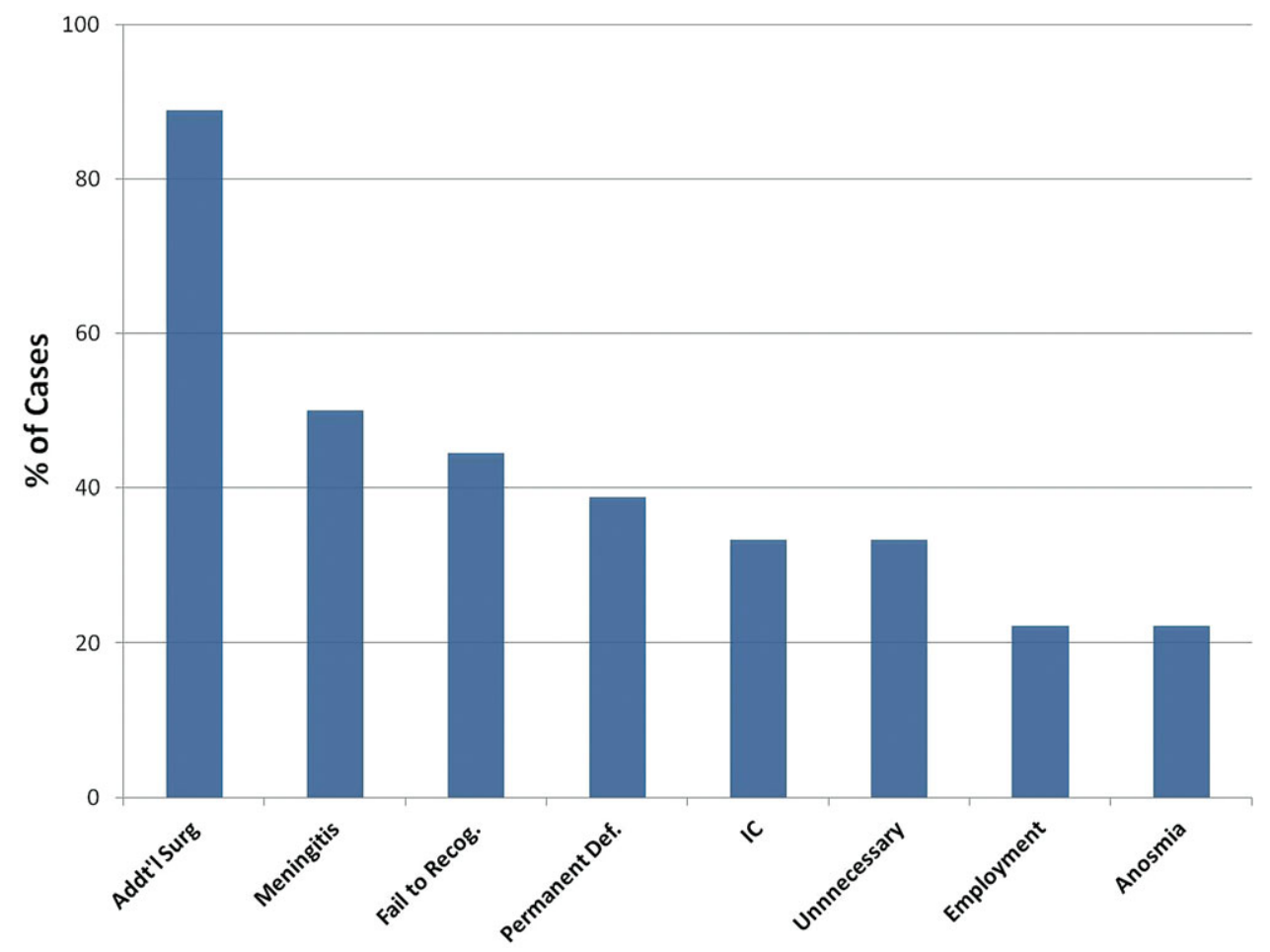

FIGURE 2. Most frequent cited alleged factors in litigation related to CSF leak. Addt'l Surg = required additional surgery for complication; Fail to Recog. = failure to recognize complication(s) in a timely manner; Permanent Def. = permanent deficit; IC $=$ informed consent; Unnecessary $=$ unnecessary procedure; Employment $=$ employment affected by injuries.

Alleged complications and reasons cited for litigation are shown in Figure 2, with the most frequent factors including having to undergo additional surgery $(88.9 \%)$, contracting meningitis $(50.0 \%)$, and a failure to recognize complications in a timely manner $(44.4 \%)$. There was 1 death in litigation involving CSF leaks, allegedly as a result of a radiologic misdiagnosis.

\section{Discussion}

In this analysis, litigation involving iatrogenic CSF leaks was most frequently associated with ESS. Despite a majority of cases being resolved in favor of physicians, other cases that resulted in damages awarded and those settled out of court had significant consequences for both plaintiffs and defendants. In the case with the largest damages awarded, the plaintiff was favored under the premise that ESS was not indicated because the defendant failed to first pursue more conservative measures. In the only other plaintiff verdict, the defendant had failed to identify and correct a post-ESS CSF leak despite 2 occurrences of meningitis. During corrective surgery of the leak, there was structural damage that resulted in total anosmia, hypogeusia, and mild damage to the frontal lobes manifesting as memory deficits.

Of the 18 cases examined in this study, there was 1 death, allegedly the result of radiologic misdiagnosis. In this case, a 62-year-old female was referred to an otolaryngologist for left nasal discharge. After referral to a neurosurgeon and substantial radiologic examination, she was diagnosed with a CSF leak originating from the cribriform plate and underwent ESS to repair the defect. Intraoperatively, a previously undiagnosed mass was found and removed after indeterminate biopsy and pathologic analysis were performed. However, she never awoke postoperatively and developed an intracerebral hemorrhage, dying 6 days later. According to the plaintiff, radiologic imaging prior to ESS confirmed the presence of the mass, providing evidence of direct causation by the defendant surgeons in the harm experienced by the patient.

Direct causation, alone, may not be sufficient to award damages. Four criteria must be fulfilled in order for damages to be awarded to a plaintiff in medical malpractice litigation. These include proving harm has occurred, direct causation between a physician's actions and this harm, the presence of a duty, and the breach of this duty. ${ }^{33}$ Failing to meet this standard means that the physician defendant is not negligent in the eyes of the law.

Several strategies can be pursued to minimize liability. A lack of informed consent was alleged in 6 of 18 cases, highlighting the need for clear communication that comprehensively addresses expectations and alternatives. Exploring more conservative measures, in collaboration with the patient, may reduce liability. Specifically, part of the initial evaluation prior to surgery should include a thorough discussion of appropriate medical therapies. Not only would this explicitly confirm avoidance of unnecessary procedures, but this discussion could then serve as a foundation for future conversations when the patient is advised 
that surgery is the best treatment. Additionally, litigation may be avoided if the consent process explicitly includes mention of potential risks, such as additional surgery and meningitis. ${ }^{34}$ Such information could be made more accessible in the form of detailed written information that patients could read and review out of the office. This way, they could be more involved and aware of warning signs, which they might be more likely to mention at follow-up examinations.

Westlaw, a comprehensive legal database widely used by legal professionals, has been previously used for analyses on specific topics in otolaryngology, including corticosteroid use, ${ }^{26}$ hearing loss, ${ }^{27}$ facial plastic surgery, ${ }^{20}$ facial nerve injury, ${ }^{28}$ and sinonasal disease. ${ }^{29}$ There are, however, several weaknesses associated with its use in such an analysis. Previous studies have indicated jury verdict and settlement reports included in Westlaw may include cases which are voluntarily submitted, ${ }^{26,27}$ with attorneys contributing this outcome information specifically to communicate outcomes and factors in determining legal responsibility. However, as previously mentioned, many if not most jurisdictions do make available nonvoluntarily submitted cases. Additionally, out-of-court settlements are likely to be underrepresented, as some may not progress far enough to be included in publically available federal and state court records. As a result, this analysis may not adequately represent overall prevalence of litigation related to CSF leaks. Despite these limitations, Westlaw remains a very valuable resource for details regarding factors in malpractice litigation, as evidenced by its use in many other analyses. ${ }^{20,26-29}$

\section{Conclusion}

Although a slight majority of cases were resolved in the defendant's favor, payments made were considerable, averaging approximately $\$ 1$ million. Strategies to decrease liability and allow patients to make more informed decisions include practicing clear communication with patients that explicitly addresses potential risks, such as contracting meningitis and having to undergo additional reparative surgery in the event of a complication. Physicians may minimize liability by implementing these strategies, and consequently limit costs associated with iatrogenic CSF leaks.

\section{References}

1. Eloy JA, Choudhry OJ, Shukla PA, Kuperan AB, Friedel ME, Liu JK. Nasoseptal flap repair afte endoscopic transsellar versus expanded endonasal approaches: Is there an increased risk of postoperative cerebrospinal fluid leak? Laryngoscope. 2012;122:1219-1225

2. Germani RM, Vivero R, Herzallah IR, Casiano RR Endoscopic reconstruction of large anterior skull base defects using acellular dermal allograft. Am J Rhinol. 2007;21:615-618.

3. Lanza DC, O'Brien DA, Kennedy DW. Endoscopic repair of cerebrospinal fluid fistulae and encephaloceles. Laryngoscope. 1996;106:1119-1125.

4. Eloy JA, Patel SK, Shukla PA, Smith ML, Choudhry OJ, Liu JK. Triple-layer reconstruction technique for large cribriform defects after endoscopic endonasal resection of anterior skull base tumors. Int Forum Allergy Rhinol. 2013;3:204-211.

5. Kaptain GJ, Kanter AS, Hamilton DK, Laws ER Management and implications of intraoperative cerebrospinal fluid leak in transnasoseptal transsphenoida microsurgery. Neurosurgery. 2011;68:144-150; discussion 150-141.

6. Eloy JA, Kuperan AB, Choudhry OJ, Harirchian S, Liu JK. Efficacy of the pedicled nasoseptal flap without cerebrospinal fluid (CSF) diversion for repair of skull base defects: incidence of postoperative CSF leaks. Int Forum Allergy Rhinol. 2012;2:397401.

7. Eloy JA, Shukla PA, Choudhry OJ, Singh R, Liu JK. Challenges and surgical nuances in reconstruction of large planum sphenoidale tuberculum sellae defects af ter endoscopic endonasal resection of parasellar skul base tumors. The Laryngoscope. 2013;123:13531360 .

8. Eloy JA, Choudhry OJ, Christiano LD, Ajibade DV, Liu JK. Double flap technique for reconstruction of anterior skull base defects after craniofacial tumo resection: technical note. Int Forum Allergy Rhinol. 2013;3:425-430.

9. Eloy JA, Choudhry OJ, Friedel ME, Kuperan AB Liu JK. Endoscopic nasoseptal flap repair of skul base defects: is addition of a dural sealant necessary? Otolaryngol Head Neck Surg. 2012;147:161166.

10. Liu JK, Schmidt RF, Choudhry OJ, Shukla PA, Eloy JA. Surgical nuances for nasoseptal flap reconstruction of cranial base defects with high-flow cerebrospinal fluid leaks after endoscopic skull base surgery. Neurosurg Focus. 2012;32:E7.

11. Eloy JA, Kalyoussef E, Choudhry OJ, et al. Salvage endoscopic nasoseptal flap repair of persistent cerebrospinal fluid leak after open skull base surgery. $A m$ J Otolaryngol. 2012;33:735-740.

12. Eloy JA, Patel AA, Shukla PA, Choudhry OJ, Liu JK. Early harvesting of the vascularized pedicled nasoseptal flap during endoscopic skull base surgery. $\mathrm{Am}$ Otolaryngol. 2013;3:188-194.

13. Horowitz G, Fliss DM, Margalit N, Wasserzug O, Gil $Z$. Association between cerebrospinal fluid leak and meningitis after skull base surgery. Otolaryngol Head Neck Surg. 2011;145:689-693.

14. Angelo F, Giuseppe M, Eliana M, Luisa C, Gennaro B. Spontaneous intracranial hypotension: diagnostic and therapeutic implications in neurosurgical practice. Neurol Sci. 2011;32(Suppl 3):S287-S290.

15. Cousins MJ, Brazier D, Cook R. Intracranial hy potension caused by cervical cerebrospinal fluid leak: treatment with epidural blood patch. Anesth Analg. 2004;98:1794-1797.

16. Wootten CT, Kaylie DM, Warren FM, Jackson CG Management of brain herniation and cerebrospinal fluid leak in revision chronic ear surgery. Laryngoscope. 2005; 115:1256-1261.

17. General Accounting Office. Medical liability: im pact on hospital and physician costs extends be yond insurance. GAO/AIMD-95-169. Washington, DC: General Accounting Office; 1995. http://www. gao.gov/assets/230/221826.pdf. Accessed March 5, 2013.

18. Anderson GF, Hussey PS, Frogner BK, Waters HR. Health spending in the United States and the rest of the industrialized world. Health Aff (Millwood). 2005;24:903-914.

19. Lynn-Macrae AG, Lynn-Macrae RA, Emani J, Kern RC, Conley DB. Medicolegal analysis of injury during endoscopic sinus surgery. Laryngoscope. jury during endoscopic

20. Svider PF, Keeley BR, Zumba O, Mauro AC, Setzen $\mathrm{M}$, Eloy JA. From the operating room to the courtroom: a comprehensive characterization of litigation related to facial plastic surgery procedures. Laryngoscope. 2013;8:1849-1853.

21. Hermer LD, Brody H. Defensive medicine, cost containment, and reform. I Gen Intern Med. 2010;25:470-473.
22. Hertz BT, Arthurs J. Malpractice rates plateauing. The only thing to fear may be fear itself. Med Econ. 2011;88:24-25, 28-29, 32 .

23. Medical malpractice litigation raises health-care cost, reduces access, and lowers quality of care. J Med Pract Manage. 2004;20:44-51.

24. Svider PF, Husain Q, Kovalerchik O, et al. Deter mining legal responsibility in otolaryngology: a review of 44 trials since 2008. Am J Otolaryngol. 2013 Jan 15. doi:pii: S0196-0709(12)00279-7. 10.1016/ j.amjoto.2012.12.005. [Epub ahead of print].

25. Burkle CM, Martin DP, Keegan MT. Which is feared more: harm to the ego or financial peril? A survey of anesthesiologists' attitudes about medical malpractice. Minn Med. 2012;95:46-50.

26. Nash JJ, Nash AG, Leach ME, Poetker DM. Medica malpractice and corticosteroid use. Otolaryngol Head Neck Surg. 2011;144:10-15.

27. Reilly BK, Horn GM, Sewell RK. Hearing loss resulting in malpractice litigation: What physicians need to know. Laryngoscope. 2013;123:112-117.

28. Lydiatt DD. Medical malpractice and facial nerve paralysis. Arch Otolaryngol Head Neck Surg. 2003;129:50-53.

29. Lydiatt DD, Sewell RK. Medical malpractice and sinonasal disease. Otolaryngol Head Neck Surg. 2008;139:677-681.

30. Svider PF, Sunaryo PL, Keeley BR, Kovalerchik O, Mauro AC, Eloy JA. Characterizing liability for cranial nerve injuries: A detailed analysis of 209 malpractice trials. The Laryngoscope. 2013;123:1156-1162. doi: 10.1002/lary.23995

31. Svider PF, Pashkova AA, Husain Q, Mauro AC Eloy JD, Baredes S, Eloy JA. Determination of Legal Responsibility in Iatrogenic Tracheal and Laryngea Stenosis. The Laryngoscope. 2013;123:1754-1758. doi: 10.1002/lary. 23997

32. Svider PF, Kovalerchik O, Mauro AC, Baredes S Eloy JA. Legal Liability in Iatrogenic Orbital Injury. The Laryngoscope 2013;123:2099-2103. doi 10.1002/lary.24000

33. Moffett P, Moore G. The standard of care: legal history and definitions: the bad and good news. West J Emerg Med. 2011;12:109-112.

34. Mallardi V. [The origin of informed consent]. Acta Otorbinolaryngol Ital. 2005;25:312-327. [Italian] 